\title{
Produção de mudas de pimenteira-do-reino em substrato comercial fertilizado com adubo de liberação lenta
}

\author{
Luiz Augusto Lopes Serrano ${ }^{1}$, Fábio Altoé Marinato², Marcelo Magiero ${ }^{3}$, Gustavo Martins Sturm ${ }^{4}$
}

\begin{abstract}
RESUMO
As doenças provocadas por patógenos de solo vêm causando sérios prejuízos à pipericultura nacional, em consequência da morte prematura das plantas. Em razão disso, o objetivo deste trabalho foi avaliar a produção de mudas de três genótipos de pimenteira-do-reino, em substrato comercial isento de solo, e determinar as doses adequadas de adubo de liberação lenta, para cada genótipo, nesse substrato. Foram produzidas mudas clonais dos genótipos 'Guajarina', 'Iaçará' e 'Cingapura', em substrato comercial composto por casca de pínus e vermiculita. Ao substrato, foram misturadas cinco doses de adubo de liberação lenta, fórmula NPK 15-09-12: 0,0; 2,5; 5,0; 7,5 e $10 \mathrm{~kg} \mathrm{~m}^{-3}$. Aos 120 dias após a repicagem, os resultados mostraram que houve diferenças de crescimento entre os genótipos para todas as características avaliadas, com exceção de altura de plantas. Houve efeito das doses do adubo para todas as características avaliadas, porém a interação entre genótipos e doses do adubo foi constatada somente para o número de folhas e massas de matérias secas do sistema radicular e total. As mudas de 'Guajarina' foram as que obtiveram maior massa de matéria seca total, enquanto as de 'Cingapura' obtiveram o menor valor. As doses do adubo que proporcionaram os valores máximos de massa de matéria seca total das mudas foram $4,4 \mathrm{~kg} \mathrm{~m}^{-3}$ para 'Guajarina'; $6,4 \mathrm{~kg} \mathrm{~m}^{-3}$ para 'Iaçará' e $5,3 \mathrm{~kg} \mathrm{~m}^{-3}$ para 'Cingapura'.
\end{abstract}

Palavras-chave: Piper nigrum L., nutrição mineral de plantas, massa de matéria seca total.

\section{ABSTRACT}

\section{Production of black pepper clonal cuttings in commercial substrate with controlled-release fertilizer}

The diseases caused by soil pathogens have brought severe losses to black pepper because of plant premature death. Thus, the objective of this work was to evaluate the production of black pepper (Piper nigrum) clonal cuttings in commercial substrate fertilized with five doses of controlled-release fertilizer. It was evaluated three genotypes 'Guajarina', 'Iaçará' and 'Cingapura', cultivated in plastic bags filled up with commercial substrate composed by pinus bark and vermiculite (without soil) fertilized with five doses of controlled-release fertilizer of the formula NPK 15-09-12: $0.0,2.5,5.0,7.5$ and $10 \mathrm{~kg} \mathrm{~m}^{-3}$. At 120 days after transplanting, the results showed growth differences among genotypes for all parameters, except plant height. The controlled-release fertilizer doses interfered on plants growth, but the interaction genotype $\mathrm{x}$ doses was observed only for leaf number, root dry matter and total dry matter. The highest values for total dry matter were recorded for $\mathrm{cv}$. Guajarina, while $\mathrm{cv}$. Cingapura showed the lowest value. The highest values for total dry matter of black pepper cuttings were obtained with the doses $4.4 \mathrm{~kg} \mathrm{~m}^{-3}$ for 'Guajarina'; $6.4 \mathrm{~kg} \mathrm{~m}^{-3}$ for 'Iaçará' and $5.3 \mathrm{~kg} \mathrm{~m}^{-3}$ for 'Cingapura'.

Key words: Piper nigrum L., mineral nutritional of plants, total dry matter.

\footnotetext{
Recebido para publicação em 21/07/2011 e aprovado em 08/08/2012

'Engenheiro-Agrônomo, Doutor. Empresa Brasileira de Pesquisa Agropecuária (EMBRAPA), Centro Nacional de Pesquisa da Agroindústria Tropical (CNPAT), Rua Doutora Sara Mesquita, 2270,60511-110, Fortaleza, Ceará, Brasil. luiz.serrano@embrapa.br (autor correspondente)

${ }^{2}$ Engenheiro-Agrônomo, Mestre. Instituto de Defesa Agropecuária e Florestal do Espírito Santo (IDAF), 29950-000, Jaguaré, Espírito Santo, Brasil. marinatofa@ yahoo.com.br ${ }^{3}$ Engenheiro-Agrônomo. Mestrando da Universidade Federal do Espírito Santo, Centro Universitário Norte do Espírito Santo (CEUNES), 29930-000, São Mateus, Espírito Santo, Brasil.marcelomagiero@ hotmail.com

${ }^{4}$ Engenheiro-Agrônomo. Mestrando da Universidade Federal do Espírito Santo, Centro de Ciências Agrárias (CCAUFES), 29500-000, Alegre, Espírito Santo, Brasil. gustavosturm@hotmail.com
}

Rev. Ceres, Viçosa, v. 59, n.4, p. 512-517, jul/ago, 2012 


\section{INTRODUÇÃO}

O Brasil figura entre os maiores produtores de pimenta-do-reino (Piper nigrum L.) do mundo. Os Estados do Pará e do Espírito Santo são os maiores produtores nacionais, respondendo, respectivamente, por 75,3 e 14,3\% da produção nacional, de 52 mil toneladas. No Estado do Espírito Santo, a pimenteira-do-reino é cultivada na região Norte, em uma área superior a 2.300 ha, destacandose os municípios de São Mateus (maior produtor nacional), Jaguaré e Nova Venécia (IBGE, 2012).

Atualmente, o fator que mais tem preocupado os pipericultores, tanto os capixabas quanto os paraenses, é a morte precoce das pimenteiras, causada pelo fungo Fusarium solani f. sp. piperis Albuquerque (Gaia et al., 2007). A fusariose tem causado sérios prejuízos, pois todos os clones cultivados são susceptíveis e as perdas econômicas são inestimáveis, desde a sua detecção no final da década de 50 no Estado do Pará (Benchimol et al., 2006).

Uma das principais medidas para evitar a introdução e a disseminação desse patógeno em lavouras é a produção e plantio de mudas sadias, caracterizadas pelo material propagativo sadio e pelo substrato isento de propágulos de doenças (Ventura \& Costa, 2004; Moura et al., 2008). Pimentel \& Lodi (1994) identificaram este problema no Estado do Acre e relataram que a produção de mudas de pimenteira-do-reino apresentava problemas relacionados com o tipo de substrato utilizado, sendo comum a ocorrência de doenças, em canteiros enraizadores, causadas por diversos fungos de solo como os dos gêneros Fusarium, Sclerotium, Rhizoctonia, Phytophtora e Phytium. Os mesmos autores verificaram, também, que a utilização de fungicidas não evitou as infecções por agentes patogênicos do solo, durante e após o processo de enraizamento das estacas, elevando-se, assim, os preços e o número de mudas fora das especificações técnicas desejáveis.

A grande maioria dos produtores de mudas de pimenteira-do-reino utiliza um substrato padrão composto por solo, areia e matéria orgânica, todos não expurgados, fato que pode estar favorecendo a disseminação da doença nas regiões produtoras. Desse modo, a utilização de substratos comerciais (compostos por materiais orgânicos, sem a presença de solo), em substituição ao substrato padrão, pode-se mostrar vantajosa, uma vez que não apresentam incidência de patógenos de solo (Kämpf, 2004).

No entanto, uma das principais características da produção de mudas em substratos comerciais é a necessidade de aplicações frequentes de nutrientes, por causa, principalmente, de sua composição química e física e da maior lixiviação dos nutrientes (Barroso et al., 2000). A aplicação frequente de nutrientes por meio de pulverizações foliares, cobertura ou fertirrigação pode resultar no aumento dos custos de produção das mudas, decorrente do aumento das operações de aplicação (mão de obra).

Os adubos de liberação lenta fornecem os nutrientes para as plantas por processo de difusão controlada, garantindo a sua disponibilização de forma adequada às exigências das plantas. Ao absorver os nutrientes, as raízes causam uma depleção na sua concentração nas proximidades da zona radicular, induzindo a um processo de liberação de nutrientes por osmose (Tomaszewska et al., 2002). Por causa dessa liberação gradual de nutrientes, há uma minimização das perdas por lixiviação.

Almeida et al. (2012), ao compararem o uso de fertilizantes convencionais e de liberação lenta em mudas cítricas, verificaram que o uso de adubo de liberação lenta promoveu crescimento mais rápido, melhoria do estado nutricional e redução das atividades operacionais no viveiro. Segundo Tomaszewska et al. (2002), o maior crescimento de plantas adubadas com adubos de liberação lenta deve-se, provavelmente, à liberação gradual dos nutrientes.

Por isso, o objetivo deste trabalho foi avaliar a produção de mudas de três genótipos de pimenteira-do-reino em substrato comercial e determinar as doses adequadas de adubo de liberação lenta, para cada genótipo, nesse substrato.

\section{MATERIAL E MÉTODOS}

O experimento foi realizado em casa de vegetação, localizada na Empresa Viveiro de Mudas Marinato, em Jaguaré, Espírito Santo (1854’21" S, 4004’58" O e 78 m).

Utilizou-se o delineamento em blocos casualizados completos, em esquema fatorial ( $3 \times 5)$. Os tratamentos foram dispostos em três canteiros (blocos), que continham uma parcela experimental de cada tratamento com dez plantas, das quais cinco foram avaliadas.

Foram produzidas mudas de três genótipos de pimenteira-do-reino: 'Guajarina', 'Iaçará' e 'Cingapura'. Para obtenção das mudas clonais, as estacas foram retiradas de plantas matrizes cultivadas em ambiente protegido, imersas por cinco minutos em solução fungicida de carbendazim ( $5 \mathrm{~mL}$ p.c. $\left.10 \mathrm{~L}^{-1}\right)$, e colocadas para secar, à sombra, por 30 minutos. Após a secagem, foram aplicados 2,0 $\mathrm{g} \mathrm{kg}^{-1}$ do regulador de crescimento ácido indolbutírico (AIB), via talco, na base das estacas. Logo em seguida, procedeu-se ao estaqueamento em canteiro de areia lavada, com o propósito de enraizamento.

Aos 60 dias após o estaqueamento, as estacas enraizadas foram selecionadas e transplantadas (repicagem) para sacolas de plástico preto, com $15 \mathrm{~cm}$ de largura e $30 \mathrm{~cm}$ de altura (volume de 2,4 L), preenchidas com o substrato comercial Plantmax $\mathrm{HT}^{\circledR}$, composto por casca de pínus moída e vermiculita. 
A análise química do substrato, para determinação dos teores de nutrientes, foi realizada por meio de digestão úmida (sulfúrica e nitroperclórica), conforme Silva (2009). Os resultados estão na Tabela 1 .

Ao substrato, foram misturadas cinco doses do adubo de liberação lenta Osmocote ${ }^{\circledR}$, fórmula NPK 15-09-12 com micronutrientes: 0,$0 ; 2,5 ; 5,0 ; 7,5$ e $10 \mathrm{~kg} \mathrm{~m}^{-3}$. O adubo utilizado apresentou $8,4 \%$ de $\mathrm{N}$-amoniacal e $6,6 \%$ de $\mathrm{N}$ nitrato, derivados de nitrato de amônio e do fosfato monoamônio; sulfato de potássio, sulfato de magnésio, borato de sódio, fosfato de ferro, Ferro EDTA, sulfato de manganês, molibdato de sódio, sulfato de cobre e sulfato e óxido de zinco.

Durante a realização do experimento, houve a necessidade de aplicação de calda fungicida à base da mistura entre clorotalonil e tiofanato-metílico (200 g p.c. $\left.100 \mathrm{~L}^{-1}\right)$, para o controle de cercospora nas plantas que não receberam o adubo de liberação lenta $\left(0 \mathrm{~kg} \mathrm{~m}^{-3}\right)$. Essas plantas apresentaram sintomas visuais de deficiência de $\mathrm{N}$, o que favoreceu o surgimento da doença (Pozza et al., 2001). Durante todo o experimento, não foram constatadas plantas com sintomas de fusariose ou doença de outro patógeno de solo.

Aos 120 dias após a repicagem, época em que os viveiristas consideram as mudas aptas ao plantio no campo (Serrano et al., 2006), foram avaliadas a altura das mudas (do colo até a gema apical), o diâmetro do caule (a 0,5 $\mathrm{cm}$ do colo), o número de folhas e o comprimento do sistema radicular. Posteriormente, as partes aéreas e os sistemas radiculares das mudas avaliadas foram separados e colocados para secar em estufa $\left(70^{\circ} \mathrm{C}\right.$ por 72 horas), para determinação das massas de matérias secas da parte aérea, do sistema radicular e total, em balança de precisão.

Os dados obtidos foram submetidos à análise de variância. As médias obtidas pelos genótipos foram comparadas pelo teste de Tukey e o efeito das doses do adubo foi ajustado pela análise de regressão polinomial, ambos a $5 \%$.

\section{RESULTADOS E DISCUSSÃO}

De acordo com a análise de variância, os resultados mostraram que houve diferenças de crescimento entre os genótipos para todas as características avaliadas, com exceção de altura de plantas (Tabela 2). Também se verificou efeito das doses do adubo para todas as características avaliadas, porém a interação entre genótipos e doses do adubo foi constatada somente para o número de folhas e massas de matérias secas do sistema radicular e total (Tabela 3). Para as demais variáveis, houve efeito significativo dos genótipos e das doses de adubo, de forma independente.

As mudas de 'Guajarina' apresentaram os maiores valores de diâmetro do caule, massa de matéria seca da parte aérea, massa de matéria seca do sistema radicular e, consequentemente, massa de matéria seca total, enquanto as mudas de 'Cingapura' apresentaram os menores valores (Tabela 2). Segundo Serrano et al. (2006), as plantas adultas de 'Guajarina' apresentam maior porte e maior diâmetro de copa do que as de 'Cingapura' e 'Iaçará', tanto que exigem maior espaçamento de plantio.

Em relação ao número de folhas, o maior valor foi obtido pelas mudas de 'Cingapura' (Tabelas 2 e 3). Apesar do maior número de folhas em relação aos demais genótipos, as folhas de menor tamanho (pequenas e estreitas) são características das plantas de 'Cingapura' (Poltronieri et al., 2005; Serrano et al., 2006). Esta menor área foliar da 'Cingapura' já foi comprovada por Partelli et al. (2007) e pode explicar o fato de essas mudas não terem apresentado maior massa de matéria seca da parte aérea, quando comparada com a das demais.

Segundo Serrano et al. (2006), os produtores tradicionais de mudas de pimenteira-do-reino - que utilizam substrato composto por solo, areia e esterco - consideram a altura das mudas ( 20 a $30 \mathrm{~cm}$ ) e o número de folhas (6 a 8) como os principais indicativos do momento em que elas estão aptas para o plantio no campo. De acordo com os resultados observados neste trabalho, as médias de altura e de número de folhas, obtidas pelas mudas dos três genótipos avaliados, apresentaram valores semelhantes aos daquelas produzidas no sistema convencional. Portanto, infere-se que o substrato comercial composto por casca de pínus moída e vermiculita pode ser utilizado para a produção de mudas de pimenteira-do-reino.

Quanto às doses de adubo de liberação lenta, foi observado efeito significativo para todas as características de crescimento das mudas. Isto indica resposta da espécie à adubação química NPK, corroborando os resultados de Veloso et al. (2000), obtidos a campo. Essa resposta à adubação variou entre os genótipos, pois foi observada interação significativa entre estes e as doses do adubo, para o número de folhas, massa de matéria seca do sistema radicular e massa de matéria seca total. Diferentes res-

Tabela 1. Resultado da análise química do substrato comercial utilizado para a produção de mudas de pimenteira-do-reino ${ }^{1}$

\begin{tabular}{|c|c|c|c|c|c|c|c|c|c|c|c|}
\hline \multirow{2}{*}{$\mathbf{p H}\left(\mathrm{H}_{2} \mathrm{O}\right)$} & $\mathbf{N}$ & $\mathbf{P}_{2} \mathbf{O}_{5}$ & $\mathrm{~K}_{2} \mathrm{O}$ & $\mathbf{C a}$ & Mg & $\mathbf{S}$ & $\mathbf{F e}$ & $\mathbf{C u}$ & Zn & Mn & B \\
\hline & \multicolumn{6}{|c|}{$\mathrm{g} \mathrm{kg}^{-1}$} & \multicolumn{5}{|c|}{$\mathrm{mg} \mathrm{kg}^{-1}$} \\
\hline 5,1 & 8,0 & 2,2 & 3,1 & 8,7 & 2,8 & 2,1 & 5.700 & 11 & 18 & 182 & 15 \\
\hline
\end{tabular}

${ }^{1}$ Análise química realizada conforme metodologia de Silva (2009). 
postas entre os genótipos de pimenteira-do-reino à aplicação de nutrientes também foram observadas na adubação mineral (Veloso et al., 2000) e na orgânica (Oliveira et al., 2007).

Nos três genótipos avaliados, foram observadas respostas do tipo quadrático, em relação ao aumento das doses do adubo, para o número de folhas e massa de matéria seca total, permitindo estimar a dose do adubo que confere o maior valor às mudas para determinada característica (Tabela 3).

Apesar de se considerar a altura das mudas e o número de folhas como os principais indicativos do momento em que elas devem ser transplantadas para o campo, Marana et al. (2008) recomendaram considerar, também, a massa de matéria seca total da planta, uma vez que o valor da altura das plantas pode ser influenciado por possíveis distorções provenientes do excesso de $\mathrm{N} \mathrm{e}$, pela competição por luminosidade (estiolamento). Deste modo, as doses do adubo de liberação lenta, fórmula NPK 15-09-12, a serem utilizadas pelos produtores de mudas de pimenteira-do-reino poderão ser aquelas que proporcionaram os maiores valores para a massa de matéria seca total das mudas: $4,4 \mathrm{~kg} \mathrm{~m}^{-3}$ para a 'Guajarina'; $6,4 \mathrm{~kg} \mathrm{~m}^{-3}$ para a 'Iaçará' e 5,3 $\mathrm{kg} \mathrm{m}^{-3}$ para a 'Cingapura'.

Para as características altura de plantas, diâmetro de caule, comprimento do sistema radicular e massa de maté- ria seca da parte aérea, o efeito da aplicação das diferentes doses do adubo de liberação lenta proporcionou respostas semelhantes entre os clones (Figura 1). Tanto para a altura das mudas, diâmetro do caule e massa de matéria seca da parte aérea foram observadas respostas do tipo quadrático, em relação ao aumento das doses do adubo, sendo as que proporcionaram os maiores valores $(34,12$ $\mathrm{cm} ; 4,39 \mathrm{~mm} \mathrm{e} 4,24 \mathrm{~g}$ ) foram 5,$8 ; 6,8$ e $6,0 \mathrm{~kg} \mathrm{~m}^{-3}$, respectivamente.

O aumento das doses do adubo promoveu diminuição no comprimento do sistema radicular das mudas de todos os genótipos (Figura 1). Essa diminuição interferiu no acúmulo de massa de matéria seca do sistema radicular de todos os genótipos, porém foi observado efeito significativo apenas nas mudas de 'Guajarina' (Tabela 3).

Os resultados obtidos neste trabalho indicam que, para a obtenção das maiores médias de massa de matéria seca total - considerado um dos principais indicativos para a sobrevivência ("pegamento") das mudas no campo (Serrano et al., 2010) - as mudas de 'Guajarina' exigiram doses menores do adubo que as demais, principalmente, em comparação com as mudas de 'Iaçará' que exigiram doses mais elevadas (Tabela 3). Veloso et al. (2000) também observaram que plantas adultas de 'Guajarina' exigiram menores doses de nutrientes do que as de 'Cingapura', para obtenção de maior rendimento de produção de pi-

Tabela 2. Características de crescimento das mudas de três genótipos de pimenteira-do-reino, produzidas em substrato comercial fertilizado com cinco doses de adubo de liberação lenta, fórmula NPK 15-09-12, aos 120 dias após a repicagem ${ }^{1}$

\begin{tabular}{lccccccc}
\hline Genótipo & ALT $(\mathbf{c m})$ & $\mathbf{D C}(\mathbf{m m})$ & $\mathbf{N F}$ & $\mathbf{C R}(\mathbf{c m})$ & MSPA $(\mathbf{g})$ & MSSR $(\mathbf{g})$ & MST $(\mathbf{g})$ \\
\hline 'Guajarina' & $30,7 \mathrm{a}$ & $4,87 \mathrm{a}$ & $11,1 \mathrm{ab}$ & $41,6 \mathrm{~b}$ & $5,14 \mathrm{a}$ & $2,12 \mathrm{a}$ & $7,26 \mathrm{a}$ \\
'Iaçará' & $28,0 \mathrm{a}$ & $4,12 \mathrm{~b}$ & $11,0 \mathrm{~b}$ & $49,2 \mathrm{a}$ & $3,17 \mathrm{~b}$ & $1,42 \mathrm{~b}$ & $4,59 \mathrm{~b}$ \\
'Cingapura' & $27,0 \mathrm{a}$ & $3,60 \mathrm{c}$ & $12,9 \mathrm{a}$ & $44,9 \mathrm{ab}$ & $2,26 \mathrm{c}$ & $0,56 \mathrm{c}$ & $2,82 \mathrm{c}$ \\
\hline Média Geral & 28,6 & 4,20 & 11,7 & 45,2 & 3,52 & 1,37 & 4,89 \\
\hline
\end{tabular}

${ }^{1}$ Médias seguidas pela mesma letra nas colunas não diferem estatisticamente, pelo teste de Tukey, a 5\% de probabilidade. ALT $=$ altura das mudas, $\mathrm{DC}=$ diâmetro do caule, $\mathrm{NF}=$ número de folhas, $\mathrm{CR}=$ comprimento do sistema radicular, MSPA = massa de matéria seca da parte aérea, MSSR = massa de matéria seca do sistema radicular e MST = massa de matéria seca total.

Tabela 3. Efeito das doses de adubo de liberação lenta, fórmula NPK 15-09-12, sobre o número de folhas, massa de matéria seca do sistema radicular e massa de matéria seca total de mudas de três genótipos de pimenteira-do-reino, aos 120 dias após a repicagem

\begin{tabular}{|c|c|c|c|c|}
\hline Genótipo & Equação de regressão (5\%) & $\begin{array}{c}\text { Coeficiente de } \\
\text { determinação } \mathbf{R}^{2}\end{array}$ & $\begin{array}{l}\text { Dose máxima } \\
\qquad\left(\mathrm{kg} \mathrm{m}^{-3}\right)\end{array}$ & Valor máximo \\
\hline \multicolumn{5}{|c|}{ Número de folhas } \\
\hline 'Guajarina' & $\hat{Y}=9,5676+1,0339 x-0,0975 x^{2}$ & 0,94 & 5,3 & 12,31 \\
\hline 'Iaçará’ & $\hat{Y}=6,1162+2,0163 x-0,1379 x^{2}$ & 0,91 & 7,3 & 13,49 \\
\hline 'Cingapura' & $\hat{Y}=8,3885+2,5264 x-0,2164 x^{2}$ & 0,81 & 5,8 & 15,76 \\
\hline \multicolumn{5}{|c|}{ Massa de matéria seca do sistema radicular (g) } \\
\hline 'Guajarina' & $\hat{Y}=2,7700-0,1299 x$ & 0,72 & 0,0 & 2,77 \\
\hline \multicolumn{5}{|c|}{ Massa de matéria seca total (g) } \\
\hline 'Guajarina' & $\hat{Y}=6,6389+0,7953 x-0,0894 x^{2}$ & 0,85 & 4,4 & 8,41 \\
\hline 'Iaçará' & $\hat{Y}=2,5054+1,0041 x-0,0783 x^{2}$ & 0,50 & 6,4 & 5,72 \\
\hline 'Cingapura' & $\hat{Y}=2,0426+0,5399 x-0,0513 x^{2}$ & 0,74 & 5,3 & 3,46 \\
\hline
\end{tabular}



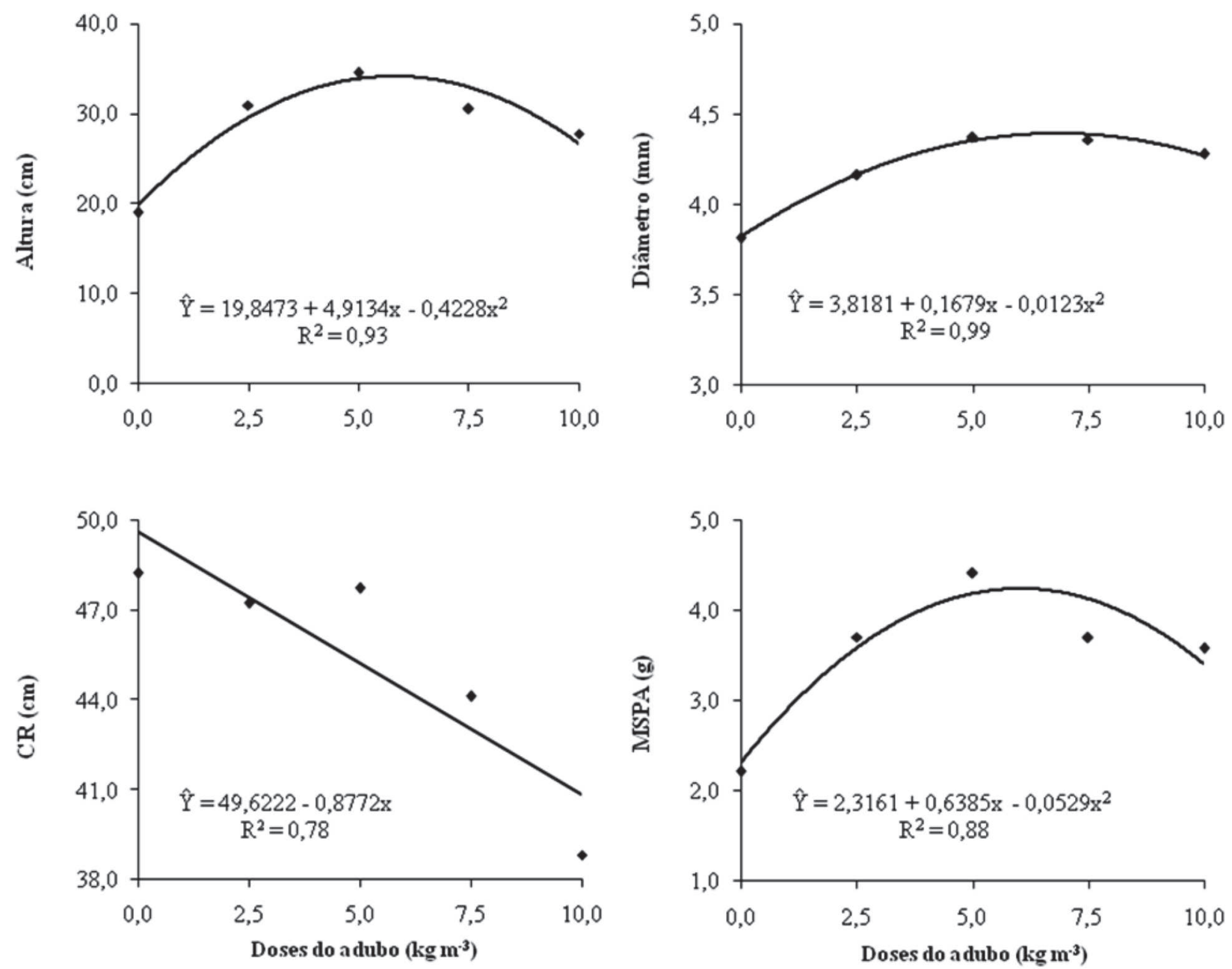

Figura 1. Efeito das doses de adubo de liberação lenta, fórmula NPK 15-09-12, sobre a altura, diâmetro do caule, comprimento do sistema radicular (CR) e massa de matéria seca da parte aérea (MSPA) de mudas de pimenteira-do-reino, aos 120 dias após a repicagem.

menta-do-reino, concluindo que a 'Guajarina' demonstra maior eficiência na utilização de adubos minerais. Já Oliveira et al. (2007) constataram que para a obtenção de maior rendimento de produção de pimenta-do-reino, as plantas adultas de 'Iaçará' exigiram maiores doses de esterco bovino do que as plantas de 'Cingapura'.

Assim, de acordo com os resultados deste trabalho, infere-se que há diferença entre as exigências nutricionais dos genótipos de pimenteira-do-reino.

\section{CONCLUSÕES}

O substrato comercial composto por casca de pínus moída e vermiculita pode ser utilizado na produção de mudas de pimenteira-do-reino.

Para esse substrato, as doses do adubo de liberação lenta, fórmula NPK 15-09-12, recomendadas para obtenção de mudas de pimenteira-do-reino com maior acúmulo de massa de matéria seca, são $4,4 \mathrm{~kg} \mathrm{~m}^{-3}$ para a 'Guajarina'; $6,4 \mathrm{~kg} \mathrm{~m}^{-3}$ para a 'Iaçará' e 5,3 $\mathrm{kg} \mathrm{m}^{-3}$ para a 'Cingapura'.

\section{AGRADECIMENTOS}

À Secretaria da Agricultura, Abastecimento, Aquicultura e Pesca do Espírito Santo (SEAG-ES), pelo apoio financeiro; ao Instituto Capixaba de Pesquisa, Assistência Técnica e Extensão Rural (INCAPER), pelo apoio logístico e estrutural; e à Sra. Terezinha Aparecida Gonçalves Meloti, pelo apoio na realização do experimento.

\section{REFERÊNCIAS}

Almeida LVB, Marinho CS, Muniz RAM \& Carvalho AJC (2012) Disponibilidade de nutrientes e crescimento de porta-enxertos de citros fertilizados com fertilizantes convencionais e de liberação lenta. Revista Brasileira de Fruticultura, 34:289-296.

Barroso DG, Carneiro JGA \& Leles PSS (2000) Qualidade de mudas de Eucalyptus camaldulensis e E. urophylla produzidas em tubetes e em blocos prensados, com diferentes substratos. Floresta e Ambiente, 7:238-250.

Benchimol RL, Sutton JC \& Dias Filho MB (2006) Potencialidade da casca de caranguejo na redução da incidência de fusariose e na promoção do crescimento de mudas de pimenteira-do-reino. Fitopatologia Brasileira, 31:180-184. 
Gaia JMD, Mota MGC, Derbyshire MTVC, Oliveira VR, Costa MR, Martins, CS \& Poltronieri MC (2007) Caracterização de acessos de pimenta-do-reino com base em sistemas enzimáticos. Horticultura Brasileira, 25:333-342.

IBGE - Instituto Brasileiro de Geografia e Estatística (2012) Produção agrícola municipal. Disponível em: <http// www.sidra.ibge.gov.br>. Acessado em: 08 de agosto de 2012.

Kämpf A (2004) Evolução e perspectivas do crescimento do uso de substratos no Brasil. In: Barbosa JG, Martinez HEP, Pedrosa MW \& Sediyama MAN (Eds.) Nutrição e adubação de plantas cultivadas em substrato. Viçosa, Universidade Federal de Viçosa. p. $3-10$.

Marana JP, Miglioranza E, Fonseca EP \& Kainuma RH (2008) Índices de qualidade e crescimento de mudas de café produzidas em tubetes. Ciência Rural, 38:39-45.

Moura EF, Menezes IC \& Lemos OF (2008) Concentrações de citocinina e carvão ativado na micropropagação de pimentado-reino. Ciência Rural, 38:72-76.

Oliveira AP, Alves EU, Silva JA, Alves AU, Oliveira ANP, Leonardo FAP, Moura MF \& Cruz IS (2007) Produtividade da pimentado-reino em função de doses de esterco bovino. Horticultura Brasileira, 25:408-410.

Partelli FL, Vieira HD \& Viana AP (2007) Estimative of black pepper leaf area with basis on the leaf blade linear dimension. Ciência Rural, 37:1458-1461.

Pimentel FA \& Lodi NV (1994) Recomendações técnicas para o enraizamento de estacas herbáceas de pimenta-do-reino nas condições edafoclimáticas do Acre. Rio Branco, EMBRAPA/ CPAF. 3p. (Comunicado Técnico, 62).
Poltronieri MC, Albuquerque FC \& Duarte MLR (2005) Sistemas de produção da pimenta-do-reino: cultivares. Disponível em: $<$ http://sistemasdeproducao.cnptia.embrapa.br/FontesHTML/ Pimenta/PimenteiradoReino/paginas/cultivares.htm>. Acessado em: 01 de março de 2011.

Pozza AAA, Martinez HEP, Caixeta SL, Cardoso AA, Zambolim L \& Pozza EA (2001) Influência da nutrição mineral na intensidade da mancha-de-olho-pardo em mudas de cafeeiro. Pesquisa Agropecuária Brasileira, 36:53-60.

Serrano LAL, Lima IM \& Martins MVV (2006) A cultura da pimenteira-do-reino do Estado do Espírito Santo. Vitória, INCAPER, 36p. (Documentos, 146).

Serrano LAL, Cattaneo LF \& Ferreguetti GA (2010) Adubo de liberação lenta na produção de mudas de mamoeiro. Revista Brasileira de Fruticultura, 32:874-883.

Silva FC (2009) Manual de análises químicas de solos, plantas e fertilizantes. $2^{\mathrm{a}}$ ed. Brasília, EMBRAPA Informação Tecnológica. $627 \mathrm{p}$.

Tomaszewska M, Jarpsoewicz A \& Karakkulski K (2002) Physical and chemical characteristics of polymer coatings in CRF formulation. Desalination, 146:319-323.

Veloso CAC, Carvalho EJM, Malavolta E \& Muraoka T (2000) Resposta de cultivares de pimenta-do-reino aos nutrientes NPK em um Latossolo Amarelo da Amazônia Oriental. Scientia Agrícola, 57:343-347.

Ventura JA \& Costa H (2004) Manejo da fusariose da pimenta-doreino no Estado do Espírito Santo. Vitória, INCAPER, 16p. (INCAPER, Documentos, 131). 